\title{
Adjusting Students' Attitude toward English Accent in China's EFL Education from the Perspective of World Englishes
}

\author{
Li Gengyan \\ School of Foreign Studies, Hubei University of Economics, Wuhan 430205, China
}

happygenggeng@hotmail.com

Keywords: EFL education; attitude; English accent; World Englishes; China English

\begin{abstract}
Faced with the social phenomenon that EFL school education in China is currently blamed for its inefficiency and it is proposed that some urgent measures should be taken to cope with this issue, the present study advocates a shift of Chinese students' attitude toward English accent. Actually Chinese speakers' attitude has gone through several changes in the past half a century due to China's contact with the West under different historical circumstances. In this paper concepts of World Englishes and China English are introduced and used as justification for adjustment of Chinese attitude. Then Chinese students' attitude toward English accent is illustrated and it is the negative feeling about their accent that hinders them from focusing on what is essentially important in English learning for EFL learners. Finally suggestions are offered for both students and teachers. It also should be noticed that a liberal attitude in EFL education will both benefit Chinese students’ English learning and the English language per se.
\end{abstract}

\section{Introduction}

After the Reform and Opening-up of China in the late 1970s, the vast majority of Chinese students began to receive EFL (English as a Foreign Language) education when they entered the junior middle school. By contrast, almost all the Chinese children nowadays begin to receive EFL education in Grade Three in the primary school and it is not uncommon to know little children commence English study outside the kindergarten. As a college English teacher in a Chinese university, the writer of this paper has been impressed with the urge of English learning of undergraduates. A large number of college students, regardless of their financial situation, have or plan to have extra English training. Expenses on English learning sometimes even lead some students to a state of deficit.

Why do so many undergraduates become enthusiastic or even fanatic about English learning? Why do some Chinese students fall into a state of English mania? Students with various backgrounds may offer different explanations, such as personal interests, preparation for studying or living abroad. Actually for most students, colleges are a step away from the society and undergraduates feel it a great urge to gain more advantages in job hunting. It cannot be denied that English has become an essential yardstick in the China's job market and Chinese undergraduates demonstrate a strong desire to earn a satisfactory position with English capability combined with professional skills. What is implied in this phenomenon? What would experts view Chinese English learning?

It is acknowledged that English is currently used by a big segment of the non-native population. It is widely agreed that China, with the biggest population in the world and a remarkable number of English learners, should take proper measures to develop EFL education, which has a significant role for the individuals' development and the country's prosperity. On the one hand, many Chinese pour their earnings and energy into English learning; on the other hand, different voices have recently echoed among ordinary Chinese people, educators and officials. With easier access to academic papers and videos about China in the western world, many foreigners have been informed that English is becoming increasingly important as one essential requirement of enrollment in Chinese colleges[1]. Nevertheless, so much emphasis on English learning has come under question. Some people argue that Chinese students should place more emphasis on learning Chinese instead of English since most of English learners still fail to communicate with foreigners with ease although excessive time, money and efforts have been spent on English learning. Actually it has 
been widely reported that an increasing number of provinces and municipalities will reduce the proportion of English in the total score of the National College Entrance Examination in the following years. Will EFL education at school take full responsibility for Chinese English performance?

In reality, it is inappropriate to blame English education on campus for the inefficiency of English learning since students as EFL learners hardly use English in daily life. Undoubtedly EFL education in school is almost the major source of input for Chinese whereas quality of English learning cannot be guaranteed without daily practice. Unlike Chinese, many Indians cannot work and live at will without English and Indians are usually found to work in the Silicon Valley in the US and airports in the UK. Thus Chinese can never make too much effort to learn English. Can English education be reformed to improve students' learning proficiency? Maybe transformation of beliefs is the first step to promotion of education effects. Next the concepts of "World Englishes" and "China English" will be introduced in detail.

\section{World Englishes and China English}

\subsection{World Englishes}

The concept of World Englishes was promoted by an Indian American scholar, Braj B. Kachru (1992), who initiated three concentric circles - the Inner Circle, the Outer Circle and the Expanding Circle. The Inner Circle refers to the base of traditional English language, including the US, UK, Ireland, Australia, New Zealand, and Canada; the Outer Circle contains Bangladesh, Ghana, India, Indonesia, the Philippines, and other countries where institutionalized varieties of English are widely used due to colonization of the UK or US; China, Japan, Saudi Arabia, Korea, Zimbabwe and other countries fall into the category of the Expanding Circle where English is a foreign language for the local people and plays an increasingly essential role in the society[2].

The norm in the Inner Circle is always regarded as the target of English language learning for non-native speakers especially in the Expanding Circle. But what is the identity of most English users nowadays? Kuo argues that English is often used in the contexts far away from the Inner Circle geographically and historically with the purpose ranging from professional dialogue to daily conversation without participation of native speakers[1]. Jenkins (1998) emphasizes that the purpose of most English learners is to successfully interact with various non-native speakers[3]. It seems that the status of non-native speakers is underlined after years of neglect. It is essentially true that non-native speakers far outnumber native speakers thus EFL education in the Expanding Circle is significant. More people have been convinced that English should be viewed as a language used and shared by people around the world, whether natives or non-natives. Under the circumstances, is it sensible to set the norm of Americans and British English as the standard of all the English learners?

\subsection{China English}

When referring to China English, many Chinese students will feel it a disgrace. Chinese students even feel humiliated when their English is considered as China English. Actually most people mistake China English for Chinese English (often abbreviated as Chinglish). What do China English and Chinese English mean?

China, as a country geographically, historically, economically, politically and culturally different from the western world especially the US and UK, needs to truly demonstrate the life in the past and at present. While probing into British and Americans' philosophy of life, Chinese also need to convey to others what they think of the world. Only in this way can cross-cultural communication be effective and meaningful. But it is easily noticed that English words and expressions at hand do not correspond with the intended meaning and more new uses are therefore born. And China English and Chinese English both result from Chinese urge to interact with the outside world. Chinese English refers to a malformed, hybrid English language which is coined by Chinese but cannot be understood by other English speakers[4]. Obviously Chinese English cannot be used in Chinese communication with foreigners and among other English learners either. By contrast, China English is also produced by Chinese but it has always been polished and approved by 
superior English learners, translators and even experts in China. Scholars (Li Wenzhong, 1993; Xie Zhijun, 1994) offer different definitions of China English and the version by Jia and Xiang (1997) is preferred: "It is an English variety used by Chinese speakers which, with the standard English as the core, bears Chinese characteristics unavoidable or beneficial for spreading Chinese culture.” [5]

With China's expanding influence in the world the stories in China have often been brought in the spot light and under scrutiny of other countries. Reporters in the western media regularly use China English to tell China's history and many westerners are more concerned about its economy, politics and people's livelihood at present. It is generally believed what is used in the major western media should be regarded as proper English and thus some China English is regarded acceptable. When it comes to China English it is easily agreed that the lexicon is the essential part but pronunciation, syntax and discourse should be involved (Li Wenzhong, 1993; Lin Qiong, 2001). In this paper Chinese speakers' accent is the focus of research and emphasis of reform.

\section{Chinese Attitude toward English Accent}

Chinese people have gradually shifted their attitude toward English accent. Since 1950s, British English has always been set as the standard for Chinese. Three factors are believed to account for this phenomenon: First, the Chinese educational system was greatly influenced by the former Soviet Union and the English curricula were set to follow its neighbour's. On the other hand, British English was almost the standard in the USSR (quoted in Xiong and Cheng, 1980); secondly, China established the diplomatic relationship with the UK earlier than the US while the Cold War, McCarthyism and the US's economic blockade might lead to Chinese negative feeling about the US and American English as well; thirdly, a few British experts worked as editors in several major English publications [6].

Since the late 1970s China has opened its door to the outside world. With more contact with the US and popularity of American culture among ordinary Chinese, American English began to gain influence in the Chinese society so both Received Pronunciation (of the UK) and General American coexisted as the standard pronunciation in China. Since the late 1990s, America's popular music and especially movies flooded into Chinese cities and more Chinese especially students demonstrated their desire to speak American English. Furthermore, the rise of the Internet stimulated youngsters to get acquainted with and even imitate the stars such as Elvis Presley, Michael Jackson, Leonardo DiCaprio, and thus strengthened Chinese demands for American English. Gradually American English seemed to surpass British English in the position in China's EFL education. The sound recordings of vocabulary and passages attached to the English textbooks are mainly performed by Americans instead of British who used to take this role.

Recently more college students have developed their individuality, which is also reflected in their attitude toward English accent. Since some British TV series and movies like Sherlock Holmes, Downton Abbey and exquisite works adapted from Jane Austen's novels and Agatha Christie's detective stories have also attracted a big group of followers, who enjoy the beautiful scenery in the UK, British actors' elegant manner and their distinctive accent as well. Therefore some college students who used to listen to the recordings by Americans begin to attentively imitate British speakers and even adjust their accent. Anyhow near-native (mainly Americans and British) is viewed as the sole standard of English learning for a vast majority of students.

With an increasing number of Chinese students studying abroad and more American and British professors coming to China for forums, workshops, seminars and other academic purposes, Chinese teachers are often informed that Chinese students overemphasize imitation of pronunciation and accuracy of grammar and over-pursue the physical appearance of language while their speaking and writing are both in want of the substantial content. Obviously Chinese students need to adjust their attitude toward EFL education and English accent in particular.

Kachru (1992) illustrates his views on varieties of English: whether a model of a language can be accepted depends on its users, who must demonstrate their solidarity, identity and loyalty to a variety; non-native speakers should cultivate an identity with a local model of English and should not consider it "deficient” or inferior; those for whom English serves as L1 or L2 need to adjust 
their attitude [7]. Actually non-native speakers especially those in the Expanding Circle like China should regulate their attitude toward non-native varieties of English including the nativised variety of their own. What is Chinese students' attitude toward their accent?

For many Chinese, China English, as a nativised English variety, is believed to be inferior to British English and American English. To be exact, most Chinese students are not satisfied with their English accent due to their mother-tongue interference. In March 2015, a research group of Hubei University of Economics in Central China's Wuhan City made a survey among 100 students of 4 classes, 25 students from each class. One item in the questionnaire offered a question: "Are you satisfied with your English accent?” The options included different degrees of satisfaction: A. Very satisfied; B. Satisfied; C. Uncertain; D. Unsatisfied; E. Very unsatisfied.

Table 1 Students' attitude toward their English accent

\begin{tabular}{|c|c|c|c|c|c|c|c|}
\hline & & \multicolumn{5}{|c|}{ Are you satisfied with your English accent? } & \multirow[t]{2}{*}{ Total } \\
\hline & & A & B & $\mathrm{C}$ & D & $\mathrm{E}$ & \\
\hline \multirow{4}{*}{ Classes } & Public Finance & 0 & 1 & 5 & 17 & 2 & 25 \\
\hline & Law & 2 & 2 & 9 & 9 & 3 & 25 \\
\hline & International Trade & 0 & 4 & 5 & 14 & 2 & 25 \\
\hline & Economics & 1 & 1 & 7 & 14 & 2 & 25 \\
\hline Total & & 3 & 8 & 26 & 54 & 9 & 100 \\
\hline
\end{tabular}

From Table 1 it is easily found that more that $60 \%$ of the students were unsatisfied or very unsatisfied with their English accent. Students in three classes with different majors showed strong negative attitude toward their accent. After almost ten years of English study these students were still troubled with their accent and there is little doubt that lack of confidence definitely hampered them from improving English proficiency. What should these students treat their accent? What suggestions can be given?

First of all, it is unnecessary to spend more energy on practice of pronunciation and intonation since almost all Chinese inevitably have shown their mother tongue in their English speaking. Most Chinese students use local dialect in the daily conversation in their childhood and thus their English accents usually indicate where they are from, such as Guangdong or Guangxi, Yunnan and Northeast China. Jenkins (1998) depicts this phenomenon as a deviant from the native model because of transfer of the native language[3]. Seidlhofer (2004) points out that non-native English speakers all have traces of the mother tongue in their accent and some are noticeable while others are slightest[8]. EFL speakers can hardly remove traces of the native language and thus Chinese students should not waste time, money and energy in shaping their speech just to achieve slightest accent.

To help students adjust their attitude, EFL teachers should intentionally offer more English input like TED talks, formal interviews or movies with different English accents. Students will be led to appreciate the contents of speech instead of pronunciation and intonation of speakers. It possibly, some videos with foreigners speaking Chinese can also be shown to prove that easy communication is more important for speakers with different native languages and accuracy of pronunciation is always neglected.

Secondly, Kirkpatrick (2007) claims that all the varieties of English are nativised English varieties and prejudice is involved in the beliefs that native speakers' and especially Anglo-American English should be taken as the standard and native English variety is always superior to nativised English variety[9]. Nowadays, more people admit that cultures around the world should be treated equal and diversity of culture should be respected and encouraged. It should not be denied that language, the carrier of culture, should also enjoy equality. While asking native speakers to abandon their prejudice against non-native varieties, EFL speakers should build self-esteem and right attitude toward English learning. Wang Rongpei (2003) suggests that Chinese overcome their psychological obstacles without fear of being ridiculed because of their "China 
English" accent. With a splendid history of culture and a rapid development of the nation, Chinese students should now be more confident about their mother language and China English as well.

Language holds three functions: communication, identity and culture. More explicitly, people use language to communicate with each other, to demonstrate who they are and which group they belong to, and to reflect culture[9]. As previously stated by Kachru[7], Chinese students should develop an identity with the nativised English variety-China English. It is widely reported that a diplomat of Singapore in the UN expressed pride of his English accent and hoped to be recognized by his fellowmen because of his Singapore English. Those who know this story are impressed with this official's self-confidence and sense of pride, which together with identity play a significant role in EFL education.

Teachers in China should deliberately introduce more Chinese with good English proficiency, such as actors, athletes, scholars and officials who have a pleasant talk with foreigners, make a speech before a large audience or receive an interview. It will be easily noted that all these speakers have different degrees of traces of their mother tongue, which does not dishearten them or confuse listeners.

Finally, Chinese students need to adjust their purpose of EFL education. Most of them argue that an English learner will be successful only when he speaks native-like English and some even feel envy at peers with near-native accent. More college students pay for English training just to speak American English. Wen advocates that Chinese students should understand all kinds of English accents and guarantee high degree of intelligibility of their English speech[10]. Furthermore content in speech and writing is comparatively more important than appearance of language. There is nothing more rewarding than conveying Chinese ideas and feelings to the rest of the world in an intelligible way. While Students get accustomed to British or American English pronunciation when listening to the texts or attending the tests, World Englishes should be included in the list of optional courses so that students will adapt to different English accents, which is a common occurrence in cross-lingual communication.

\section{Conclusion}

Chinese, as EFL learners, need to pay more to improve English proficiency compared with ESL (English as a Second Language) learners. It is essential for Chinese to develop right attitude toward EFL education and English accent in particular. Some Chinese make great effort in order to achieve native-like accent, but without avail. Apparently it is unnecessary to be indulged in imitation of accent since cross-cultural communication is the final objective of English learning, and fluency and thought in speaking and writing should be given more weight than near-native accent alone. Thanks to the theory of World Englishes, China English, as a nativised variety, offers justification for Chinese English learning. Chinese speakers' English accent allows Chinese to cultivate an identity and a sense of belonging. With the common core of English pronunciation, diversity of English accent not only stimulates EFL learners in the Expanding Circle to further their English learning but also helps to foster vigour and vitality of English language through innovation.

\section{References}

[1] Kuo, I-ChunV. “Addressing the issue of teaching English as a lingua franca”, ELT Journal Vol. 60, pp. 213-221, 2006.

[2] Kachru, Braj B. “World Englishes: approaches, issues and resources”, Language Teaching Vol. 25, pp. 1-14, 1992.

[3] Jenkins, Jennifer. "Which pronunciation norms and models for English as an International Language?” ELT Journal Vol. 52, pp. 119-126, 1998

[4] Li, Wenzhong. “China English and Chinglish”(In Chinese), Foreign Language Teaching and Research Iss. 4, pp. 18-24, 1993. 
[5] Jia, Guanjie \& Xiang Mingyou. “Justifying China English”(In Chinese). Foreign Languages and Their Teaching Iss. 5, pp. 11-12, 1997.

[6] Cheng, Chin-Chuan. “Chinese varieties of English”, in Braj B. Kachru, ed., The other tongue: English across Cultures, $2^{\text {nd }}$ edition, pp. 162-177, Urbana and Chicago: University of Illinois Press, 1992.

[7] Kachru, Braj B. "Models for non-natives Englishes”, in Braj B. Kachru, ed., The other tongue: English across Cultures, 2nd edition, pp. 48-74, Urbana and Chicago: University of Illinois Press, 1992

[8] Seidlhofer, B. "Research perspectives on teaching English as a lingua franca”, Annual Review of Applied Linguistics Iss. 24, pp. 209-239, 2004.

[9] Kirkpatrick, Andy. World Englishes: implications for international Communication and English language teaching. Cambridge: Cambridge University Press, 2007.

[10] Wen, Qiufang. “A pedagogical model for the teaching of English as an international language”(In Chinese). Curriculum, teaching material and method. Vol. 32, pp. 77-81, 2012. 